\title{
DENTAL AND MANDIBULAR RADIO-DENSITY VARIATIONS IN CHILDREN WITH AUTISM SPECTRUM DISORDERS
}

\author{
Ghada Abdel Hamid El Baz * and Gihan Gamal El Desouky **
}

\begin{abstract}
Background: Children with ASDs pose the greatest challenge for pediatric dentists due to their complex and varied oral and dental manifestations.

Aim: the present study was designed to compare the degree of dental root development of permanent teeth and the mandibular radio-density of a group of children with ASDs with healthy children.

Materials and methods: Thirty children (6-8 years) were included in this study, fifteen of the children had been previously been diagnosed with ASDs (autistic group B) while the other fifteen were healthy children (control group A). Digital panoramic radiographs for all children were obtained for bilateral measurement of the root length and the apical width of the lower permanent first molars and central incisors. In addition, the radio-density of the mandibular bone at the symphysis and the angle regions was evaluated.
\end{abstract}

Results: Group B showed statistically significant shorter mean root length values than the group A for the first permanent molars. While for apical root width; group B showed statistically significant wider mean apical width values than group A for both permanent central incisors and first molars. Regarding the mandibular radio-density, the autistic group showed statistically significant lower mean values than the control group at both, angle of the mandible and the sympheseal areas.

Conclusion: Children with ASDs experience significant delayed dental development and lower mandibular bone radio- density compared to normal children.

KEYWORDS: Autism spectrum disorders-Dental development-mandibular radio-density.

\section{INTRODUCTION}

Autism spectrum disorders (ASDs) are a set of complex neuro-developmental disorders that are characterized by impaired social interaction, difficulties in communication, and restricted, repetitive stereotype interests and activities ${ }^{1}$. Signs of ASDs begin during early childhood, it is generally manifested during the first three years of age, and usually last throughout a person's life ${ }^{2}$.

* Assistant Professor of Pediatric and Preventive Dentistry and Dental Public Health, Faculty of Dentistry, Suez Canal University. ** Assistant Professor of Oral Radiology, Faculty of Dentistry, Suez Canal University. 
The incidence of ASDs has risen sharply since the year 2000. The reported incidence of ASDs was $1 / 150$ school-aged children but in 2014, it had risen to $1 / 68$ and boys are estimated to be affected $4-5$ times as often as girls. This increase in the reported incidence is largely attributable to the changes in diagnostic practices, referral patterns, availability of services, and public awareness ${ }^{3}$. Considering the complex nature of ASDs, a single cause is unlikely. There may be many different factors leading to its development such as environmental factors, infections, errors in metabolism, cerebral accidents, hard births, immunology and genetic factors, any of which can make a child more likely to have ASDs ${ }^{4-6}$.

Children with ASDs pose the greatest challenge for pediatric dentists due to their complex and varied oral and dental manifestations. The major dental problems in ASDs are caries, gingival and periodontal diseases, damaging oral habits such as bruxism, tongue thrusting, lip biting, self-injurious behavior and orthodontic problems ${ }^{7}$. Researchers believe that children with ASDs are at risk of poor bone development, therefore, many studies have focused on bone health and its involvement with ASDs ${ }^{8,9}$. In 2008, Hedinger et $\mathrm{al}^{8}$ found that boys with ASDs were at higher risk of thinner and less dense cortical thickness of bones when compared to a group of boys of the same age who do not have ASDs. Nevertheless, there is still unclear and inadequate information about whether there are any variations in dental development or affection of jaw bone among children with ASDs. Therefore, the present study was designed to compare the degree of dental root development of permanent teeth and the mandibular radio-density of a group of children with ASDs to healthy children. We hypothesized that children with ASDs would display lower jaw radio-density and would be associated with underdeveloped roots of permanent teeth compared to those without ASDs.

\section{MATERIALS AND METHODS}

\section{Study Design}

The present cross sectional study was conducted on thirty boys and girls ranging in age between 6 and 8 years. Fifteen of the children (11 boys- 4 girls) included in the study had been previously diagnosed with ASDs by their pediatrician or by a child psychologist. They were on gluten-free and caseinfree diets and/or other medications prescribed by their physician for control of their condition, while the other fifteen were apparently healthy children $(8$ boys-7 girls) without ASDs. All children attended the Pedodontic department, Faculty of Dentistry, Suez Canal University requiring dental treatment and care. Treatment plan was explained to the parent or guardian and a written consent was obtained from the parents/guardian of the children before any clinical or radiographic procedure. The children included in the present study were chosen to fulfill the following inclusion criteria:

- Apparently healthy children (except for ASDs in the study group) free from any systemic disease that could affect tooth development.

- Absence of congenitally missing permanent teeth.

- Bilateral eruption of permanent mandibular central incisors and permanent first molars.

- Relatively co-operative children.

Digital panoramic radiographs for all children included in the present study were obtained using the same panoramic machine, ORTHOPHOS XG 5 DS/Ceph (Sirona Dental systems, Bensheim, Germany) using the pre-set pediatric program (P 10 with reduced width and height of the radiation field) and the following parameters; $62 \mathrm{Kvp}, 8 \mathrm{~mA}$ and 11.5 seconds exposure time, which were considered fixed for all radiographs taken. 


\section{Sample grouping}

The children were divided into two groups:

Group A: Control group including the digital panoramic radiographs of 15 healthy children.

Group B: Autistic group including the digital panoramic radiographs of 15 children diagnosed with ASDs.

\section{Quantitative Image Analysis}

The digital panoramic radiographs were assessed using the Digora 2.5 software (Orion Coperation, Sordex Medical, Helsinki, Finland) for bilateral measurement of the root length and the apical width of the lower permanent central incisors and permanent first molars. In addition, the same software was also used for obtaining the radio-density of the mandible at the symphysis and the angle of the mandible regions. All panoramic images were assessed twice by the same radiologist at two different sessions with two weeks period inbetween the sessions to eliminate any intra-observer reliability. The means of both trials was used for further statistical analysis.

\section{Linear measurements}

Linear measurements of root length and width of apical opening were performed using the software linear measurement tool for the selected teeth as follows: (Fig. 1)
- A horizontal line was drawn to join the most mesial to the most distal cemento-enamel junction of the tooth under investigation.

- Another horizontal line was drawn at the developing root apex joining the most mesial to the most distal apical opening, parallel to the line joining the cemento-enamel junction, and measured to obtain the apical width.

- At exactly the midpoint of the apical width, a vertical line was drawn perpendicular to the cemento-enamel line representing the root length of the tooth under investigation ${ }^{10}$.

\section{Radio-density measurements of the mandible}

The Digora software was again used to evaluate the radio-density of the mandible at the midline (symphyseal area) and at the angle of the mandible regions. The radio-density measurements were calibrated by quantifying the image on a 256 grey scale where 0 represented totally radiolucent and 255 represented totally radiopaque regions. (Fig. 2)

- A rectangle area $(34 \times 30)$ was drawn at the lower incisors region exactly at the midline, 2 millimeters apical to the developing incisors at the symphysis of the mandible and the mean grey level was recorded.

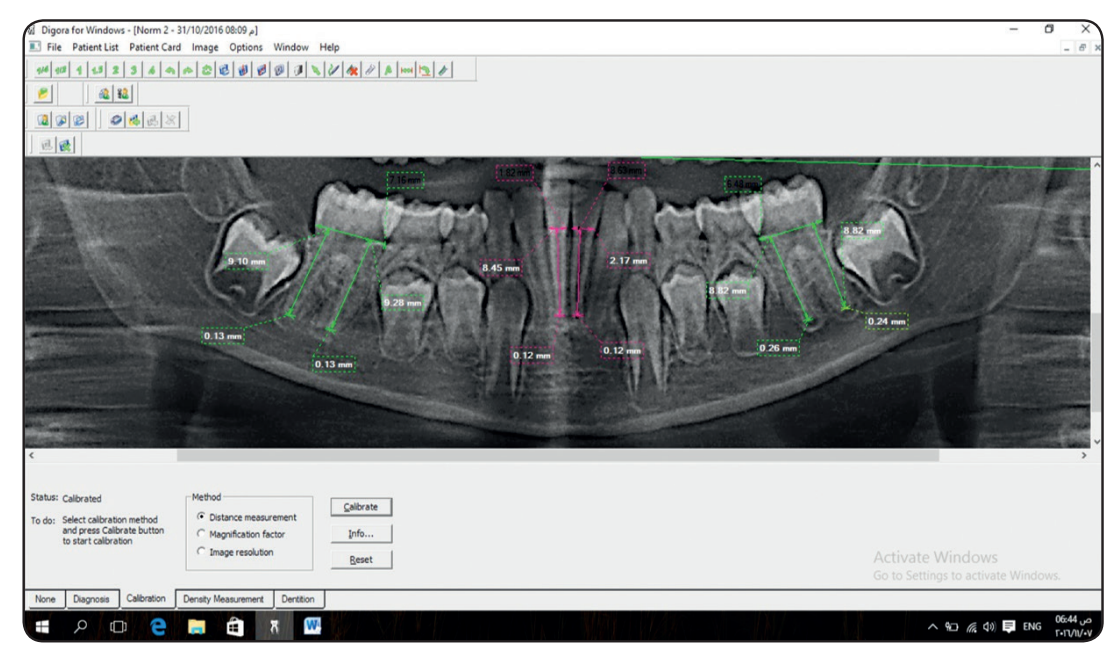

Fig. (1) A digital panoramic radiograph of 8 year old boy in group B (autistic group) showing the apical width and root length measurements obtained for the mandibular permanent central incisors and first molars. 


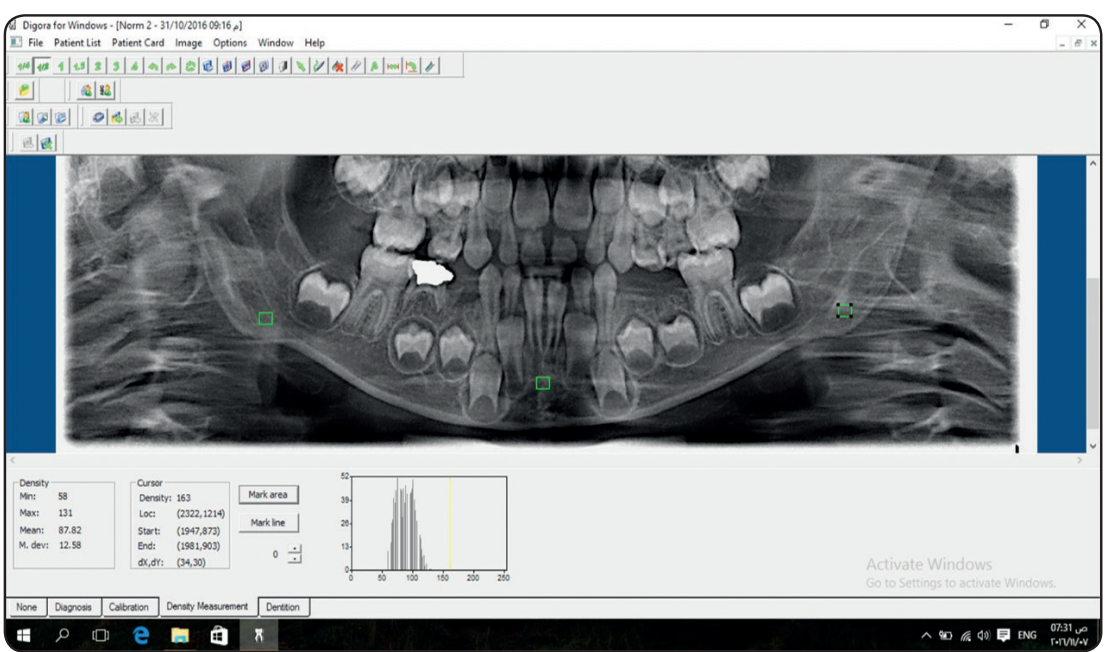

- Similarly, another rectangle area (34x30) was drawn at the angle body of the mandible region, 2 millimeters above the lower border of the mandible and 2 millimeters medial to the ascending ramus, (away from the crypt of the developing second molar and below the inferior alveolar canal) and the mean grey level was recorded.

\section{Statistical Analysis}

The results were recorded, tabulated, and statistically analyzed using IBM ${ }^{\circledR}$ SPSS $^{\circledR}$ Statistics Version 20 for Windows.

Numerical data were explored for normality by checking the distribution of data and using tests of normality (Kolmogorov-Smirnov and ShapiroWilk tests). Root length measurements of bilateral permanent first molar and lower central incisor as well as bone density data showed parametric distribution while apical width measurements showed non-parametric distribution. Data were presented as mean, median, standard deviation (SD), minimum, maximum and 95\% Confidence Interval (95\% CI) for the mean values. For parametric data, Student's t-test was used to compare between the two groups. For non-parametric data, Mann-Whitney U test was used to compare between the two groups. The significance level was set at $\mathrm{P} \leq 0.05$.
Fig. (2) A digital panoramic radiograph of 7 year old boy in group B (autistic group) showing the radiodensity measurements at the symphysis and the angle body of the mandible.

\section{RESULTS}

\section{A-Demographic data}

Regarding gender, there was no statistically significant difference between gender distributions in the two groups $(\mathrm{P}$-value $=0.350)$. The mean age and standard deviation values of the control group A was $7 \pm 0.8$ years, while in the autistic group B, the mean age was $6.9 \pm 0.9$ years. There was no statistically significant difference between mean age values in the two groups $(\mathrm{P}$-value $=0.795)$.

\section{B-Linear measurements}

\section{First molar measurements}

As regards mesial as well as distal root lengths; the Autistic group B showed statistically significant shorter mean root length values than the control group A. While for apical width of mesial as well as distal roots; Autistic group B showed statistically significant wider mean apical width values than control group A. (Table 1, fig 3).

\section{Lower central incisor measurements}

As regards root length; there was no statistically significant difference between mean root length values in the two groups. While for apical width; the Autistic group showed statistically significant wider mean apical width value than the control group. (Table 2, fig 4) 
TABLE (1) Comparison between the first permanent molar linear measurements in the two groups A and B (in $\mathrm{mm}$ )

\begin{tabular}{|c|c|c|c|c|c|c|c|c|c|}
\hline \multirow{2}{*}{ Measurement } & \multirow{2}{*}{ Group } & \multirow{2}{*}{ Mean } & \multirow{2}{*}{$\mathrm{SD}$} & \multirow{2}{*}{ Median } & \multirow{2}{*}{ Minimum } & \multirow{2}{*}{ Maximum } & \multicolumn{2}{|c|}{$95 \% \mathrm{CI}$} & \multirow{2}{*}{$P$-value } \\
\hline & & & & & & & Lower bound & Upper bound & \\
\hline \multirow{2}{*}{$\begin{array}{l}\text { Mesial root } \\
\text { length }\end{array}$} & Autistic & 7.34 & 1.12 & 7.08 & 6.19 & 8.90 & 6.54 & 8.14 & \multirow{2}{*}{$0.016^{*}$} \\
\hline & Control & 8.45 & 0.70 & 8.58 & 7.26 & 9.41 & 7.95 & 8.95 & \\
\hline \multirow{2}{*}{$\begin{array}{c}\text { Apical width of } \\
\text { mesial root }\end{array}$} & Autistic & 0.55 & 0.28 & 0.40 & 0.29 & 1.12 & 0.35 & 0.75 & \multirow{2}{*}{$<0.001 *$} \\
\hline & Control & 0.19 & 0.06 & 0.19 & 0.13 & 0.31 & 0.15 & 0.24 & \\
\hline \multirow{2}{*}{$\begin{array}{l}\text { Distal root } \\
\text { length }\end{array}$} & Autistic & 7.28 & 1.07 & 7.08 & 6.17 & 8.71 & 6.52 & 8.04 & \multirow{2}{*}{$0.021 *$} \\
\hline & Control & 8.33 & 0.78 & 8.59 & 6.92 & 9.42 & 7.78 & 8.89 & \\
\hline \multirow{2}{*}{$\begin{array}{l}\text { Apical width of } \\
\text { distal root }\end{array}$} & Autistic & 0.56 & 0.26 & 0.43 & 0.33 & 1.05 & 0.38 & 0.74 & \multirow{2}{*}{$<0.001^{*}$} \\
\hline & Control & 0.20 & 0.06 & 0.18 & 0.13 & 0.30 & 0.15 & 0.24 & \\
\hline
\end{tabular}

\section{*: Significant at $P \leq 0.05$}

TABLE (2) Comparison between lower permanent central incisor linear measurements in the two groups A and $B$ (in $\mathrm{mm})$

\begin{tabular}{|c|c|c|c|c|c|c|c|c|c|}
\hline \multirow{2}{*}{ Measurement } & \multirow{2}{*}{ Group } & \multirow{2}{*}{ Mean } & \multirow{2}{*}{$\mathrm{SD}$} & \multirow{2}{*}{ Median } & \multirow{2}{*}{ Minimum } & \multirow{2}{*}{ Maximum } & \multicolumn{2}{|c|}{$95 \% \mathrm{CI}$} & \multirow{2}{*}{$P$-value } \\
\hline & & & & & & & Lower bound & Upper bound & \\
\hline \multirow{2}{*}{ Root length } & Autistic & 7.37 & 1.12 & 7.38 & 5.94 & 8.67 & 6.56 & 8.17 & \multirow{2}{*}{0.066} \\
\hline & Control & 8.25 & 0.87 & 8.47 & 6.67 & 9.53 & 7.62 & 8.87 & \\
\hline \multirow{2}{*}{ Apical width } & Autistic & 0.56 & 0.32 & 0.50 & 0.24 & 1.24 & 0.33 & 0.79 & \multirow{2}{*}{$0.001 *$} \\
\hline & Control & 0.17 & 0.10 & 0.12 & 0.09 & 0.45 & 0.10 & 0.25 & \\
\hline
\end{tabular}

\section{*: Significant at $P \leq 0.05$}

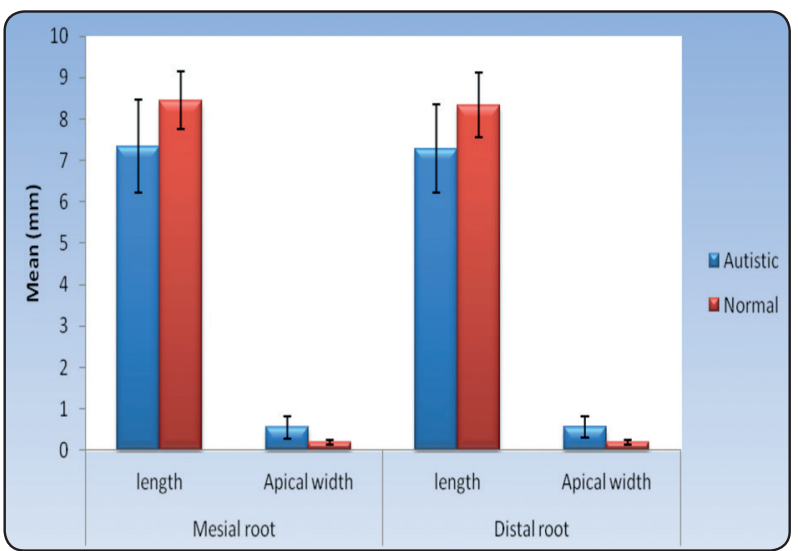

Fig (3) Bar chart representing mean and standard deviation values of the first molar measurements in the two groups A and B

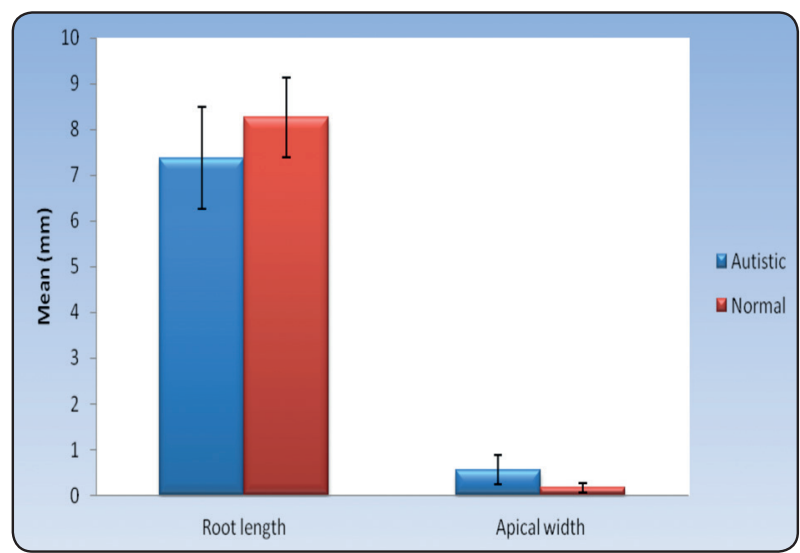

Fig. (4) Bar chart representing mean and standard deviation values of lower central incisor measurements in the two groups 
TABLE (3) Comparison between mandibular bone radio-density measurements in the two groups (A and B)

\begin{tabular}{|c|c|c|c|c|c|c|c|c|c|}
\hline \multirow[b]{2}{*}{ Site } & \multirow[b]{2}{*}{ Group } & \multirow{2}{*}{ Mean } & \multirow{2}{*}{ SD } & \multirow{2}{*}{ Median } & \multirow{2}{*}{ Minimum } & \multirow{2}{*}{ Maximum } & \multicolumn{2}{|c|}{$95 \% \mathrm{CI}$} & \multirow{2}{*}{$P$-value } \\
\hline & & & & & & & Lower bound & Upper bound & \\
\hline \multirow{2}{*}{$\begin{array}{l}\text { Angle body } \\
\text { mandible }\end{array}$} & Autistic & 67.89 & 4.60 & 67.97 & 59.81 & 74.53 & 64.60 & 71.18 & \multirow{2}{*}{$0.035^{*}$} \\
\hline & Control & 72.28 & 3.99 & 72.73 & 64.00 & 76.85 & 69.42 & 75.13 & \\
\hline \multirow{2}{*}{ Symphysis } & Autistic & 65.38 & 4.14 & 64.68 & 60.46 & 72.88 & 62.42 & 68.34 & \multirow{2}{*}{$0.014 *$} \\
\hline & Control & 70.09 & 3.55 & 70.64 & 64.44 & 75.31 & 67.55 & 72.63 & \\
\hline
\end{tabular}

\section{*: Significant at $P \leq 0.05$}

\section{C-Mandibular radio-density measurements}

At both, the angle of the mandible and at the symphyseal area; Autistic group showed statistically significant lower mean radio-density values than the control group. (Table 3, fig 5)

\section{DISCUSSION}

Over the past two decades, there has been an increase in reporting cases of ASDs. Knowledge and awareness of the condition have increasingly grown worldwide at all levels, among the general public, parents, health professionals, and the research community ${ }^{11}$. This led to a surge in research studies targeting children with ASDs in an attempt to improve their lives and that of their families ${ }^{12}$. The present study was carried out to compare the degree of dental root development of permanent teeth and the mandibular radio-density of a group of children with ASDs to that of normal children.

In this study, as hypothesized, it was found that children with ASD had under developed roots of the selected permanent teeth and lower mandibular bone radio-density compared with controls. Radiographic examination was necessary to achieve the aim of the present study. Although the periapical radiograph, taken using the paralleling technique, is considered the clinical gold standard for measuring root length ${ }^{13-14}$, it would have been impossible to place a film inside the mouth of an autistic child.

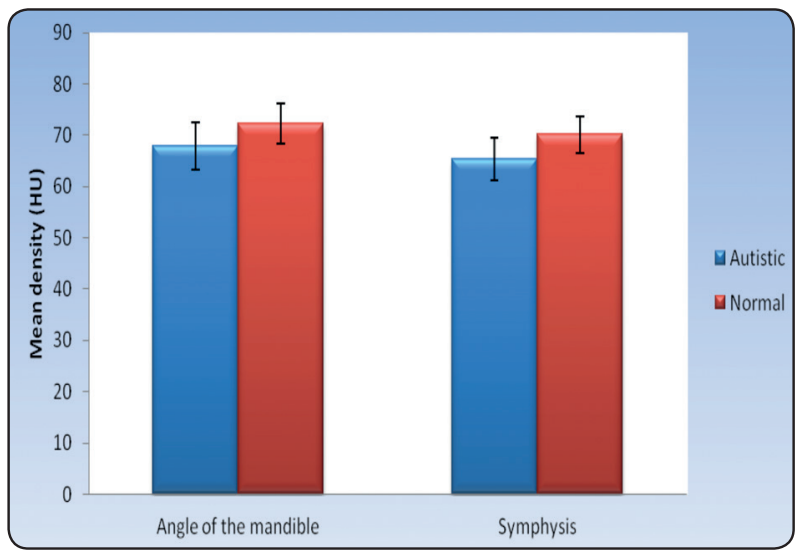

Fig. (5) Bar chart representing mean and standard deviation values of bone density measurements in the two groups

Hence, the choice of digital panoramic radiograph, which in addition to significantly reducing radiation dose to the child in comparison to conventional radiography, less children cooperation was required, therefore, it was easier to perform for children with ASDs; especially with the auditory and sensory hyper-sensitivity present in those children ${ }^{15-16}$.

Results of the present study showed statistically significant shorter root length of the first permanent molars in autistic group B in comparison to the control group A. However, regarding the apical width; group B showed statistically significantly wider apical width than group A for both, the first permanent molars and the central incisors roots. 
Many children with ASDs have mood disorders and /or seizures. Those children are placed on medications such as anticonvulsants or atypical antipsychotics, which may negatively impact their nutritional status. The most affected nutrients were calcium and vitamin $\mathrm{D}$, which are necessary for bone and teeth development. Therefore, with longterm use of medications in children with ASDs, impaired osteoid synthesis, odontogenesis process and calcification, osteoporosis, fracture and rickets have been reported ${ }^{17}$. The longitudinal development of the first molar roots is generally completed by the age of 8 to 9 years. The early time of drug administration appears to have a degree of influence on the development of root length and apical width of permanent teeth, consequently their eruption ${ }^{18}$. In addition, tooth eruption may be delayed in children with ASDs due to phenytoin-induced gingival hyperplasia. Phenytoin is a commonly prescribed drug for people with ASDs ${ }^{12,19}$.

Regarding mandibular radio- density, results of our study revealed lower mean radio-density values at both, the angle of the mandible and the sympheseal areas in the autistic group B in comparison to the control group A. Children with ASDs have high rates of co-morbid neurologic and psychiatric illnesses which may be associated with increased cortisol levels, exacerbating the risk for low bone density ${ }^{20-21}$. Moreover, due to the increased gastro-intestinal (GI) symptoms in these children, treatments focusing on elimination diets as gluten or casein free diets have been commonly used to decrease the frequency of symptoms and to better regulate GI function ${ }^{22}$. These diets, especially caseinfree and lactose-free diets, the major dietary source of calcium and vitamin D in young children cause potential risk for decreased bone development and sub-optimal bone mineralization ${ }^{23-24}$. In accordance with the results of the present study, Neumeyer et al $2013^{9}$ conducted a comparative study to assess the bone mineral density in pre-pubertal boys with ASDs using dual energy X-ray absorptiometry
(DXA) and found that boys with ASDs have lower bone density than controls. They attributed the results of their study to decreased vitamin D intake and lack of adequate physical exercise seen in children with ASDs.

The findings of the present study have still to be the subject of further research to assess their impact on the oral and dental health of children with ASDs. The major limitations of our study were the small sample size due to the scarce number of children diagnosed with ASDs attending the Pedodontic department, in addition to the expected difficulties in the implementation of digital panoramic radiograph in those children. The relatively limited number of previous available studies conducted on the radiographic representation of dental development and jaw density of children with ASDs was another difficulty facing the authors.

\section{CONCLUSION}

Children with ASDs may experience delayed dental development and lower mandibular radiodensity compared to normal children.

\section{REFERENCES}

1. El Khatib AA, El Tekeya MA, El Tantawi MA and Omar T. Oral health status and behaviors of children with Autism Spectrum Disorder: a case-control study. International Journal of Paediatric Dentistry 2014;24:314-23.

2. American Psychiatric Association. Diagnostic and Statistical Manual of Mental Disorders, Fifth Edition. Arlington, VA: American Psychiatric Association; 2013.

3. Bradley Schaefer G. Clinical Genetic Aspects of Autism Spectrum Disorders. International Journal o f Molecular Sciences 2016; 180: 1-14.

4. Farber JM. Autism and other communication disorders In: Capute AJ, Accardo PJ, eds. Developmental disabilities in infancy and childhood. 2d ed. Baltimore, Md.: Brookes 1996; 347-64.

5. Minshew NJ. Brief report: brain mechanism in autism: functional and structural adnormalities. J Autism Dev Disord 1996;26:205-9 
6. Schaefer G.B. and Mendelsohn N.J. Genetics evaluation for the etiologic diagnosis of autism spectrum disorders. Genetics in Medicine 2008; 10: 4-12.

7. Weddell JA, Sanders BK, Jones JE. Dental problems of children with disabilities. In: McDonald RE, Avery RD. (eds). Dentistry for the Child and Adolescent. $8^{\text {th }}$ edn. St. Louis: Mosby-Year Book Inc 2004; 460-86.

8. Hedinger ML, England LJ, Molloy CA, Yu KF, ManningCourtney P, Mills JL. Reduced bone cortical thickness in boys with autism or autism spectrum disorder. Journal of Autism and Developmental Disorders 2008; 38: 848-56.

9. Neumeyer AM, Gates A, Ferrone C, Lee H, Misra M. Bone density in peripubertal boys with autism spectrum disorders. J Autism Dev Disord 2013; 43:1623-29.

10. Sherrard JF, Rossouw PE, Benson BW, Carrillo R, Buschang PH. Accuracy and reliability of tooth and root lengths measured on cone-beam computed tomographs. American Journal of Orthodontics and Dentofacial Orthopedics 2010; 4: 100-8.

11. Dover CJ, Le Couteur A. How to diagnose autism. Arch Dis Child 2007;92: 540-45.

12. Udhya J, Varadharaja M, Parthiban J, Ila Srinivasan. Autism Disorder (AD): An Updated Review for Paediatric Dentists. Journal of Clinical and Diagnostic Research 2014; 8:275-79

13. Sameshima GT, Sinclair PM. Predicting and preventing root resorption: part I. Diagnostic factors. Am J Orthod Dentofacial Orthop 2001; 119:505-10.

14. Årtun J, Smale I, Behbehani F, Doppel D, Van't Hof M, Kuijpers-Jagtman AM. Apical root resorption six and 12 months after initiation of fixed orthodontic appliance therapy. Angle Orthod 2005; 75:919-26.

15. Langland OE, Langlais RP and Preece JW. Principles of dental imaging. 2nd ed. Baltimore: Williams and Wilkins: 2002.
16. Halenur Onat,Gül Tosun,Yağmur Şener. Dental Treatment in Asperger Syndrome. Journal of Dental and Medical Sciences 2014; 13:80-2.

17. Homer C and Shine N. Nutrition Management of Pediatric Epilepsy. In: Nevin-Folino NL, Amore-Spalding K, Nieman L. Pediatric Manual of Clinical Dietetics. 2nd ed. Chicago, IL: Pediatric Nutrition Practice Group, American Dietetic Association 2008; 425-27.

18. Delli K, Reichart PA, Bornstein MM and Livas C. Management of children with autism spectrum disorder in the dental setting: Concerns, behavioural approaches and recommendations. Med Oral Patol Oral Cir Bucal 2013; $18: 862-88$

19. Luppanapornlarp S, Leelataweewud P, Putongkam P, Ketanont S Periodontal status and orthodontic treatment need of autistic children. World J Orthod 2010; 11: 256-61.

20. Sheth RD, Binkley N, Hermann BP. Progressive bone deficit in epilepsy.Neurology 2008; 70:170-76.

21. Greaves-Lord K, Huizink AC, Oldehinkel AJ, Ormel J, Verhulst FC, Ferdinand RF. Baseline cortisol measures and developmental pathways of anxiety early adolescence. Acta Paediatrica Scandinavia 2009; 120:178-86.

22. Levy SE, Souders MC, Ittenbach RF, Giarelli E, Mulberg AE, Pinto-Martin JA. Relationship of dietary intake to gastrointestinal symptoms in children with autistic spectrum disorders. Biological Psychiatry 2007; 61: 492-97.

23. Altenburger J, Geraghty ME, Wolf K, Taylor CA, Lane AE. The quality of nutritional intake in children with autism. Journal of the American Dietetic Association 2010; 11:40-4.

24. Geraghty ME, Depasquale GM, Lane AE. Nutritional intake and therapies in autism: a spectrum of what we know Infant Child \& Adolescent Nutrition journal 2010; 2:62-9 